\title{
A STUDY ON ANATOMY AND VARIATIONS OF SINOATRIAL NODAL ARTERY
}

\author{
Raniprabha Sukumaran ${ }^{1}$, Usha Krishnan Kuruppath ${ }^{2}$ \\ ${ }^{1}$ Assistant Professor, Department of Anatomy, Government Medical College, Kottayam. \\ ${ }^{2}$ Associate Professor, Department of Anatomy, Government Medical College, Kottayam.
}

\begin{abstract}
BACKGROUND

The sinoatrial nodal artery is anatomically significant because it is the landmark for the identification of the sinoatrial node (SA node), which is the natural pacemaker of heart. Origin of the SA nodal artery is highly variable. Its close relation with the atrium may lead to iatrogenic injury and ischaemia to SA node causing arrhythmias.

The aim of the present study is to assess the normal anatomy and variations of SA nodal artery by studying the number, origin, course, length and distance of its origin from the ostium of parent artery.
\end{abstract}

\section{MATERIALS AND METHODS}

This descriptive study was done on 75 embalmed hearts stored in the Department of Anatomy at Government Medical College, Kottayam, during the period 2016 - 2017. Any heart with clearly visible abnormalities was excluded from the study.

Dissection was carried out as follows- The pericardium was stripped off. RCA, LCA and their branches to SA node were dissected from their origin to termination. The number, point of origin and course of SA nodal artery were studied. The length and distance of origin from the ostium of parent artery were measured with the help of a measuring scale.

\section{RESULTS}

In the study, the artery to SA node was single in 70 hearts (93.33\%). Double SA nodal artery was noted in 5 hearts (6.67\%). In 60 hearts, it originated from RCA (80\%), in 9 hearts from circumflex branch of LCA (12\%). In one heart SA nodal artery took origin from left coronary artery, where the artery trifurcated into circumflex, left anterior descending and SA nodal. Precaval course was the most common $(60 \%)$.

\section{CONCLUSION}

A thorough knowledge of anatomy and variations of the artery would help cardiologists to take necessary precautions to prevent ischaemia of the SA node, atrial walls and atrial septum.

\section{KEYWORDS}

Right Coronary Artery, Left Coronary Artery, Circumflex Branch, SA Node, SA Nodal Artery, Right Atrium, Superior Vena Cava, Arrhythmia, Flutter.

HOW TO CITE THIS ARTICLE: Sukumaran R, Kuruppath UK. A study on anatomy and variations of sinoatrial nodal artery. J. Evolution Med. Dent. Sci. 2017;6(71):5065-5068, DOI: 10.14260/Jemds/2017/1101

\section{BACKGROUND}

The sinoatrial nodal artery is anatomically significant, because it is the landmark for the identification of the sinoatrial node (SA node), which is the natural pacemaker of heart. The artery of SA node is an atrial branch distributed to both atria, mainly the right. Origin of the SA nodal artery is highly variable. In most of the cases it is a branch of right coronary artery (RCA), but in 35\% cases it may arise from circumflex branch of left coronary artery (LCA). During its course, SA nodal artery (SANA) passes back in the groove between right auricular appendage and aorta. Then it divides into branches around the base of superior vena cava. ${ }^{1}$

Most of the previous studies reported a single SA nodal artery. In such cases, compensation cannot occur if it is being cut off or occluded. Ischaemia can cause arrhythmias like atrial flutter or sick sinus syndrome.

Financial or Other, Competing Interest: None.

Submission 28-07-2017, Peer Review 22-08-2017,

Acceptance 28-08-2017, Published 04-09-2017.

Corresponding Author:

Dr. Usha Krishnan Kuruppath,

Associate Professor,

Department of Anatomy,

Government Medical College, Kottayam

E-mail:drushakk@gmail.com

DOI: $10.14260 /$ jemds $/ 2017 / 1101$
In addition, the close relationship of the artery with the atrium can result in injury during atrial surgery.

Considering the variability of SA nodal artery and its susceptibility to injury during surgery, we decided to investigate the anatomy of the artery in normal human hearts.

The aim of the present study is to assess the normal anatomy and variations of SA nodal artery by studying the number, origin, course, length and distance of its origin from the ostium of parent artery.

\section{MATERIALS AND METHODS}

A total of 75 embalmed hearts of both sexes between the ages of 20 - 70 years stored in the Department of Anatomy, Government Medical College, Kottayam were used for this study during the period 2016 - 2017. Any heart with clearly visible abnormalities was excluded from the study.

Dissection was carried out as follows:

The pericardium was stripped off. RCA, LCA and their branches to SA node were dissected from their origin to termination. The number, point of origin and course of SA nodal artery were studied. The length and distance of origin from the ostium of parent artery were measured with the help of a measuring scale. 


\section{RESULTS}

1) Number of SA Nodal Artery

In 70 cases, the artery was found to be single vessel (93.33\%) which supply SA node. Dual blood supply was seen in 5 cases $(6.67 \%)$.

2) Origin of SA Nodal Artery

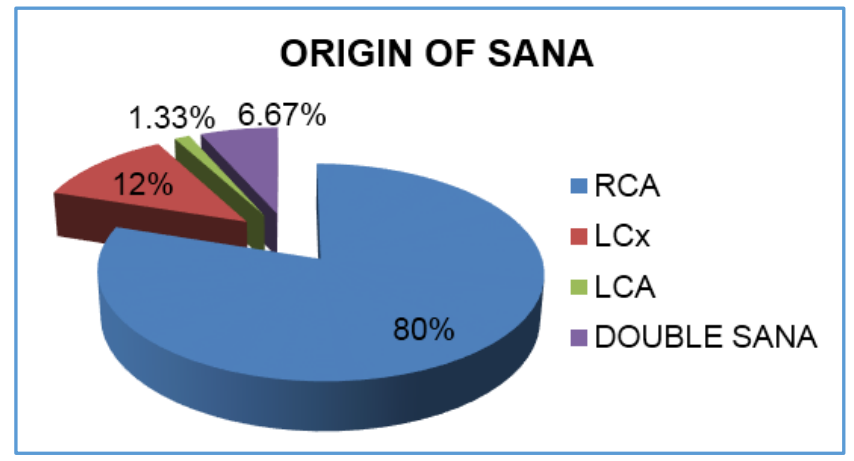

Table 1

Among 75 hearts studied, SA nodal artery originated from RCA in 60 cases (80\%). In 9 hearts $(12 \%)$, it was found to be arising from Circumflex branch of LCA (LCx). In one heart, SANA originated directly from trunk of LCA $(1.33 \%)$. In this case, the LCA trifurcated into LCx, SANA and Left Anterior Descending artery (LAD). In 5 hearts, SA node was supplied by both RCA and LCx (6.67\%).

3) Average distance of Origin of SANA from Ostium of RCA and LCX

\begin{tabular}{|c|c|c|}
\hline Artery & $\begin{array}{c}\text { Mean Distance from } \\
\text { Ostium }\end{array}$ & Range \\
\hline SANA from RCA & $1.68 \mathrm{~cm}$ & $0.1-4.4 \mathrm{~cm}$ \\
\hline SANA from LCx & $0.88 \mathrm{~cm}$ & $0.2-2.8 \mathrm{~cm}$ \\
\hline \multicolumn{3}{|c|}{ Table 2 } \\
\hline
\end{tabular}

Most of the SANA originated from proximal part of RCA and LCx. In case of right SANA, the origin was proximal to origin of right marginal artery in all the hearts. In one heart, one atrial branch of RCA bifurcated into SANA and then distributed to right atrium. The SANA originated from trunk of left coronary artery showed a distance of $0.2 \mathrm{~cm}$ from left coronary trunk.

\section{4) Length of the Artery}

\begin{tabular}{|c|c|c|}
\hline Artery & Mean Length & Range \\
\hline SANA from RCA & $3.45 \mathrm{~cm}$ & $1.5-5.5 \mathrm{~cm}$ \\
\hline SANA from LCx & $4.83 \mathrm{~cm}$ & $3-5.8 \mathrm{~cm}$ \\
\hline \multicolumn{3}{|c|}{ Table 3 } \\
\hline
\end{tabular}

Average length of SANA was more on the left side, because the artery travelled more distance to reach SA node. In case of double SANA, mean length of SANA from LCx was $4.8 \mathrm{~cm}$ and from RCA was $3.5 \mathrm{~cm}$. The length of SANA from the trunk of LCA measured $5.8 \mathrm{~cm}$.

5) Course of SANA in Relation to the Root of SVC

\begin{tabular}{|c|c|c|}
\hline Relation to SVC & No. of Hearts & Percentage (\%) \\
\hline Precaval & 45 & $60 \%$ \\
\hline Retrocaval & 23 & $30.6 \%$ \\
\hline Pericaval & 8 & $10.6 \%$ \\
\hline \multicolumn{3}{|c|}{ Table 4 } \\
\hline
\end{tabular}
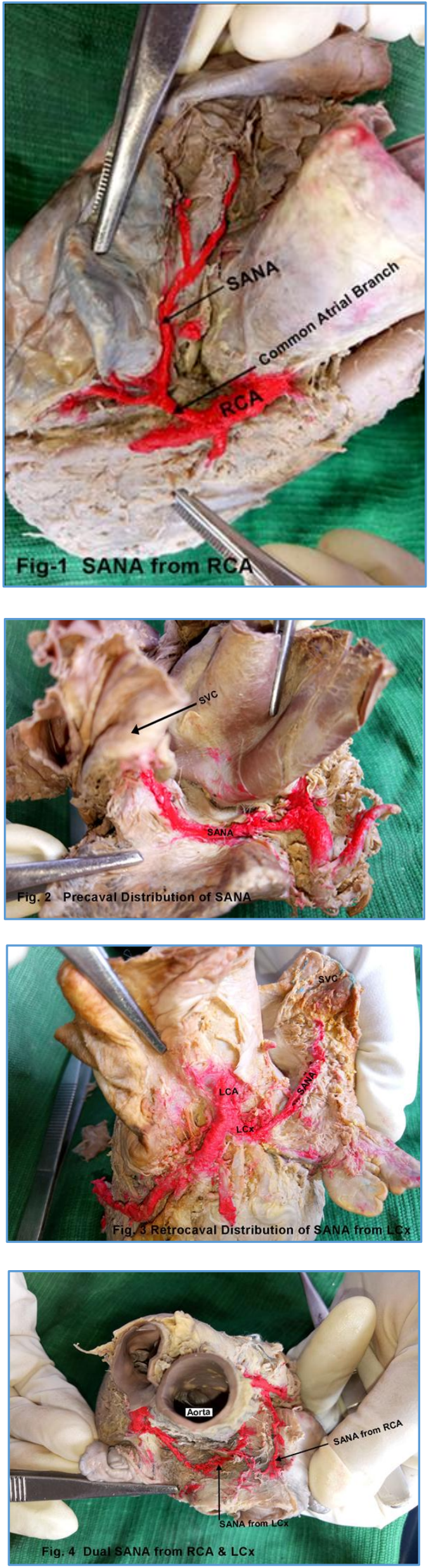

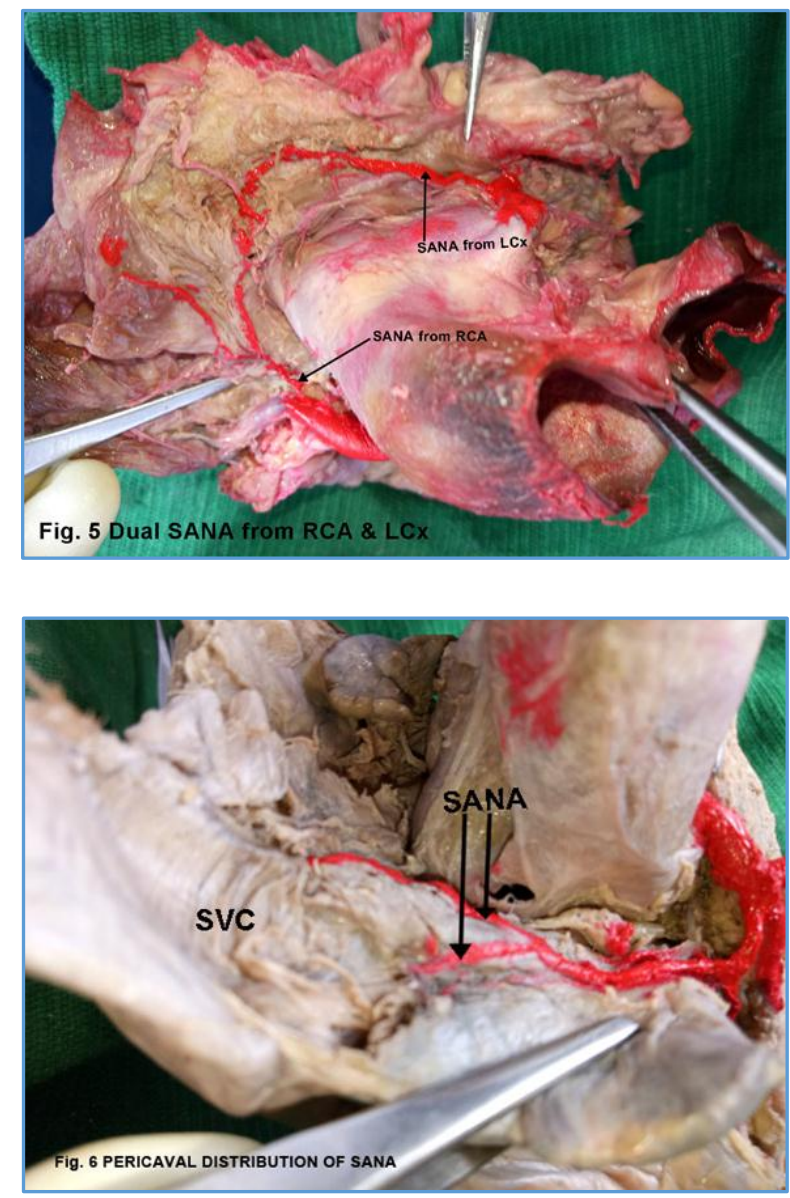

\section{DISCUSSION}

Since the original description given by Keith and Flack (1907), the SA node has been known to have a special arterial supply. ${ }^{2}$

Sow et al studied SA nodal artery by injection dissection method and found that it was solitary artery in $88.89 \%$ of the cases and double in $11.11 \%$ cases. $^{3}$ In the present study, 70 SANAs (93.33\%) were found to be solitary and $5(6.67 \%)$ were dual arteries.

Saremi et al reported that a single Sinoatrial nodal artery arose from RCA in $65.7 \%$ cases and from LCx in $27.4 \%$ cases, dual blood flow was noted in $5.9 \%$ cases. ${ }^{4}$

Origin of SANA was reported by several authors previously.

\begin{tabular}{|c|c|c|c|c|}
\hline $\begin{array}{c}\text { Sl. } \\
\text { No. }\end{array}$ & $\begin{array}{c}\text { Name of } \\
\text { Author }\end{array}$ & $\begin{array}{c}\text { SANA from } \\
\text { RCA (\%) }\end{array}$ & $\begin{array}{c}\text { SANA from } \\
\text { LCx (\%) }\end{array}$ & $\begin{array}{c}\text { SANA from } \\
\text { both (\%) }\end{array}$ \\
\hline 1 & $\begin{array}{c}\text { Lakshmi } \\
\text { Ramanathan }\end{array}$ & 53 & 42 & 4.33 \\
\hline 2 & Divyaprakash $^{6}$ & 57.2 & 40.14 & 2.66 \\
\hline 3 & Futami C $^{7}$ & 73 & 3 & 23 \\
\hline 4 & Berdajs $^{8}$ & 66 & 34 & 0 \\
\hline 5 & $\begin{array}{c}\text { Abdur Rafe } \\
\text { Abdul Waheed }\end{array}$ & 71.25 & 28.75 & 0 \\
\hline 6 & Shilpa Bhimalli1 & 66.6 & 25 & 3.5 \\
\hline 7 & Present study & 80 & 12 & 6.67 \\
\hline Table 5. Origin of SANA compared with Previous Studies \\
\hline
\end{tabular}

In all studies, SANA was found to be originating from RCA in most cases. The second most common origin was from LCx.
Our study also showed similar finding. We found SANA originating from trunk of LCA in one heart (1.33\%). In this case the LCA trifurcated into Left Anterior Descending (LAD), LCx and SANA.

In cases of dual origin of SANA, the most common pattern was one branch arising from RCA and the other from LCx. Such dual supply would prevent ischaemia in vaso-occlusive disease of one of the coronary arteries. When a single artery supplies the SA node, there is more chance of ischaemia leading to sick sinus syndrome.

We did not observe any extra cardiac origin of SANA. This finding is similar to Onciu M et al. ${ }^{11}$ But Jose Roberto Ortale et al and some other authors reported extra cardiac origin of SANA, in which the SA nodal artery arose from arteries other than coronary arteries. They also reported cases with 3 SANA (2\%) in their study. ${ }^{12}$

Futami et al reported $23 \%$ incidence of dual irrigation to SA node in Japanese population. It may be considered as a variation with a particular ethnic group. The presence of such anatomical variation like dual blood supply should be carefully evaluated preoperatively to prevent iatrogenic injury to one of the branches.

James (1961) had described the origin of SANA directly from the aortic sinuses. ${ }^{13}$ Interventional cardiologists must be aware of the presence of multiple ostia in anterior aortic sinuses before doing procedures like right ventriculotomy for ventricular septal defect or pulmonary stenosis.

According to Anjali Sabnis et al, the mean distance between the origin of SANA and origin of RCA was $35 \mathrm{~mm}$. The average length of Right SANA was $35 \mathrm{~mm}$. The mean length of SANA from LCx was $70 \mathrm{~mm} \cdot{ }^{14}$

Saremi et al found the distance between ostium of LCX and Left SANA ranged from $2-35 \mathrm{~mm}{ }^{4}$

Ortale et al reported that the longest distance between the ostium of RCA and origin of SANA from RCA is $48.6 \mathrm{~mm}$.

But the study done by Ozturk et al proved that longest distance was $62 \mathrm{~mm}$ between the ostium of RCA and origin of SANA. ${ }^{15}$

In the present study, we could observe a wide variation in the distance between the site of origin of SANA and ostium of RCA. The mean distance of origin from RCA measured was $1.68 \mathrm{~cm}$ and the longest distance measured was $4.4 \mathrm{~cm}$. In one case, the artery was just proximal to the origin of right marginal artery. The mean distance from ostium of LCx was $0.88 \mathrm{~cm}$.

The mean length of SANA from RCA was $3.45 \mathrm{~cm}$ and that from LCx was $4.83 \mathrm{~cm}$. The longest SANA was from LCA and it measured $5.8 \mathrm{~cm}$.

Long Jiang Zhang et al classified SANA into 3 types (Right, Left, Posterior) and 9 subtypes (Precaval, Pericaval and Retrocaval) according to its origin and termination. ${ }^{16}$

In the present study, course of the SANA was noted. It was found that Precaval course was most common in the present study. It was observed in 45 SANA (60\%). Retrocaval course was the second most common (23 hearts- 30.6\%). Pericaval course was seen in $10.6 \%$ cases ( 8 hearts). Retrocaval course of RCA is rare, because the Right SANA has to take a developmental turn of nearly $180^{\circ}$ in between the aorta and SVC if it becomes retrocaval.

Kon and Associates reported that a good exposure of the mitral valve and its subvalvular apparatus was obtained by superior trans-septal approach. ${ }^{17}$ According to Smith CR, this 
approach may lead to injury to SANA as the incision passes through the postero-superior border of interatrial septum. ${ }^{18}$

Further study on this is done by Berdajs. He confirmed that SANA crosses the postero-superior border of inter-atrial septum in $54 \%$ cases. He selected the SVC and posterior inter-atrial sulcus as landmarks to describe the course of SANA. Posterior inter-atrial sulcus indicates postero-superior border of inter-atrial septum. The septum was crossed by all left SANAs. Among right SANAs, retrocaval and pericaval arteries were prone to surgical trauma. Precaval course of the artery is considered to be safe. ${ }^{8}$

Nerantzis and Avgoustakis described the presence of a long "S" shaped artery in $8 \%$ of all hearts. ${ }^{19}$ The artery arose from postero-lateral part of LCx below and behind the left auricle. It passes posteriorly between the left auricle and ostium of left pulmonary vein. Then it passes anteriorly close to anterior wall of left atrium. The artery is at high risk of intraoperative damage during Cox-Maze surgery for atrial fibrillation. ${ }^{20}$

As the SANA is highly variable, a thorough knowledge of its anatomy would help cardiologist in accurate interpretation of coronary angiogram. Nerantzis et al observed that SANA supplies atrial myocardium and septum in $59 \%$ cases. $^{21}$ Any interruption of blood flow in the artery may lead to ischaemia and infarction of atrial wall and septum.

\section{CONCLUSION}

In our study, the artery to SA node was single in 70 hearts $(93.33 \%)$. Double SA nodal artery was noted in 5 hearts (6.67\%). In 60 hearts, it originated from RCA (80\%), in 9 hearts from circumflex branch of LCA (12\%). In one heart, SA nodal artery took origin from Left coronary artery where the artery trifurcated into Circumflex, Left anterior descending and SA nodal. Precaval course was the most common (60\%). A thorough knowledge of anatomy and variations of the artery would help cardiologists to take necessary precautions to prevent ischaemia of the SA node, atrial walls and atrial septum.

\section{List of Abbreviations}

RCA- Right Coronary Artery; LCA- Left Coronary Artery; LCxCircumflex branch from LCA; SANA- Sinoatrial Nodal Artery; SVC- Superior Vena Cava.

\section{REFERENCES}

[1] Standring S. Gray`s anatomy. 40 th edn. London, Churchill Livingstone, Elsevier, 2008:978-80.

[2] Keith A, Flack M. The form and nature of the muscular connections between the primary divisions of the vertebrate heart. J Anat Physiol 1907;41(Pt 3):172-89.

[3] Sow ML, Ndoye JM, Lo EA. The artery of the sinoatrial node, anatomic considerations based on 45 injectiondissections of the heart. Surg Radiol Anat 1996;18(2):103-9.
[4] Saremi F, Abolhoda A, Ashikyan 0, et al. Arterial supply to sinuatrial and atrioventricular nodes: imaging with multidetector CT. Radiology 2008;246(1):99-107.

[5] Ramanathan L, Shetty P, Nayak SR, et al. Origin of the sinoatrial and atrioventricular nodal arteries in South Indians: an angiographic study. Arq Bras Cardiol 2009;92(5):314-9.

[6] Divyaprakash M, Suma MP, Jagadish HR, et al. Branching pattern of sinoatrial and atrioventricular nodal arteries in patients undergoing cardiac catheterization in a tertiary care hospital. Int J Adv Med 2016;3(4):835-7.

[7] Futami C, Tanuma K, Tanuma $Y$, et al. The arterial blood supply of the conducting system in normal human hearts. Surg Radiol Anat 2003;25(1):42-9.

[8] Berdajs D, Patonay L, Turina MI. The clinical anatomy of the sinus node artery. Ann Thorac Surg 2003;76(3):732-5.

[9] Waheed ARA, Shaikh SI, Diwan CV. Origin of SA nodal artery: an angiographic study. Int J Recent Trends in Science and Technology 2013;7(3):141-2.

[10] Dixit D, Siddibhavi M, Shirol VS. A study of variations in coronary arterial system in cadaveric human heart. World J of Science and Technology 2011;1(5):30-5.

[11] Onciu M, Tuta LA, Baz R, et al. Specifics of the blood supply of the sinoatrial node. Rev Med Chir Soc Med Nat Iasi 2006;110(3):667-73.

[12] Ortale JR, Paganoti CF, Marchiori GF. Anatomical variations in the human sinuatrial nodal artery. Clinics (Sao Paulo) 2006;61(6):551-8.

[13] James TN. Anatomy of the human sinus node. Anat Rec 1961;141:109-39.

[14] Sabnis AS, Silotry NN. Anatomical variations of nodal arteries in human hearts. J of Evolution of Medical and Dental Sciences 2012;1(4):482-6.

[15] Ozturk E, Saglam M, Bozlar U, et al. Arterial supply of the sinoatrial node: a CT coronary angiographic study. Int J Cardiovascular Imaging 2011;27(4):619-27.

[16] Zhang LJ, Wang YZ, Huang W, et al. Anatomical investigation of sinus node artery using dual-source computed tomography. Circ J 2008;72(10):1615-20.

[17] Kon ND, Tucker WY, Mills SA, et al. Mitral valve operation via an extended transseptal approach. Ann Thorac Surg 1993;55(6):1413-7.

[18] Smith CR. Efficacy and safety of the superior septal approach to the mitral valve. Ann Thor Surg 1993;55:1357-8.

[19] Nerantzis C, Avgoustakis D. An S shaped atrial artery supplying the sinus node area. An anatomic study. Chest 1980;78(2):274-8.

[20] Saremi F, Channual S, Abolhoda A, et al. MDCT of the Sshaped sinoatrial node artery. AJR Am J Roentgenol 2008;190(6):1569-75.

[21] Nerantzis CE, Avgoustakis D, Toutouzas P. The importance of the sinus node artery in blood supply of the atrial myocardium. An anatomical study of 360 cases. Acta Cardiol 1983;38(1):35-47. 